\title{
The evaluation of the disease advancement in patients with mucopolysaccharidosis
}

\author{
Violetta Opoka-Winiarska \\ From 21st European Pediatric Rheumatology (PReS) Congress \\ Belgrade, Serbia. 17-21 September 2014
}

\section{Introduction}

One of the most important manifestations of mucopolysaccharidosis (MPS) type I, II and VI is a progressive disease of the osteoarticular system. The evaluation of the disease advancement is difficult due to the complexity of symptoms. The characteristic features are progressive limitation of joint mobility and joint pain. These symptoms affect the quality of patient life. A uniform scale has not been developed for these patients.

\section{Objectives}

The aim of this study was to use the experience in the evaluation of disorders in rheumatic diseases (Juvenile Idiopathic Arthritis, JIA) in patients with MPS.

\section{Methods}

6 patients with MPS VI were evaluated: 2 with advanced disease, 2 with moderate and 2 with slow progressing disease. The following parameters were selected for assessment: Physician global assessment of disease activity (PGA), Patient/parent global assessment of well-being (PGE), Functional ability (CHAQ), Number of joints with limited movement (LJC) and VAS pain - visual analogue scale for pain.

\section{Results}

The evaluation results are shown in Table 1 .

\section{Conclusion}

The parameters used in JIA may be applied for assessment of the MPS severity. With their implementation, the progression of the disease and the effect of the treatment can be assessed and compared.

\section{Disclosure of interest}

None declared

Published: 17 September 2014

doi:10.1186/1546-0096-12-S1-P153

Cite this article as: Opoka-Winiarska: The evaluation of the disease advancement in patients with mucopolysaccharidosis. Pediatric

Rheumatology 2014 12(Suppl 1):P153.

Table 1

\begin{tabular}{|c|c|c|c|c|c|c|c|c|}
\hline Patient & $\begin{array}{c}\text { Age } \\
\text { (years) }\end{array}$ & $\begin{array}{c}\text { PGA } \\
0-10 \mathrm{~cm}\end{array}$ & $\begin{array}{c}\text { PGE } \\
0-10 \mathrm{~cm}\end{array}$ & $\begin{array}{c}\text { CHAQ } \\
0-3\end{array}$ & $\begin{array}{l}\text { LJC } \\
0-71\end{array}$ & $\begin{array}{l}\text { VAS pain } \\
0-10 \mathrm{~cm}\end{array}$ & $\begin{array}{l}\text { Score } \\
(104)\end{array}$ & Severity of disease \\
\hline 1 & 35 & 1.0 & 0 & 0.375 & 2 & 1.0 & 4.375 & mild \\
\hline 2 & 21 & 2.0 & 0 & 1.125 & 2 & 0 & 5.125 & $\downarrow$ \\
\hline 3 & 9 & 2.0 & 0 & 0 & 7 & 2.0 & 9 & $\downarrow$ \\
\hline 4 & 16 & 2.0 & 0 & 0.125 & 8 & 0 & 10.125 & $\downarrow$ \\
\hline 5 & 5 & 3.0 & 1,0 & 0 & 21 & 1.0 & 26 & $\downarrow$ \\
\hline 6 & 11 & 3.0 & 0 & 0.125 & 37 & 3.5 & 43.625 & advanced \\
\hline
\end{tabular}

Department of Pediatric Pulmonology and Rheumatology, Medical University 